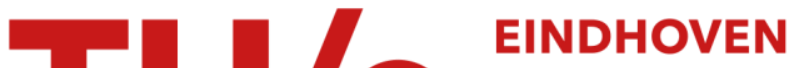 \\ UNIVERSITY OF \\ TECHNOLOGY
}

\section{Thermal cracking of substituted aromatic hydrocarbons I. Kinetic study of the thermal cracking of i-propylbenzene}

Citation for published version (APA):

Chen, Q., \& Froment, G. F. (1991). Thermal cracking of substituted aromatic hydrocarbons I. Kinetic study of the thermal cracking of i-propylbenzene. Journal of Analytical and Applied Pyrolysis, 21, 27-50.

https://doi.org/10.1016/0165-2370\%2891\%2980014-Y, https://doi.org/10.1016/0165-2370(91)80014-Y

DOI:

10.1016/0165-2370\%2891\%2980014-Y

$10.1016 / 0165-2370(91) 80014-Y$

Document status and date:

Published: 01/01/1991

Document Version:

Publisher's PDF, also known as Version of Record (includes final page, issue and volume numbers)

Please check the document version of this publication:

- A submitted manuscript is the version of the article upon submission and before peer-review. There can be important differences between the submitted version and the official published version of record. People interested in the research are advised to contact the author for the final version of the publication, or visit the $\mathrm{DOI}$ to the publisher's website.

- The final author version and the galley proof are versions of the publication after peer review.

- The final published version features the final layout of the paper including the volume, issue and page numbers.

Link to publication

\section{General rights}

Copyright and moral rights for the publications made accessible in the public portal are retained by the authors and/or other copyright owners and it is a condition of accessing publications that users recognise and abide by the legal requirements associated with these rights.

- Users may download and print one copy of any publication from the public portal for the purpose of private study or research.

- You may not further distribute the material or use it for any profit-making activity or commercial gain

- You may freely distribute the URL identifying the publication in the public portal.

If the publication is distributed under the terms of Article $25 \mathrm{fa}$ of the Dutch Copyright Act, indicated by the "Taverne" license above, please follow below link for the End User Agreement:

www.tue.nl/taverne

Take down policy

If you believe that this document breaches copyright please contact us at:

openaccess@tue.nl

providing details and we will investigate your claim. 


\title{
Thermal cracking of substituted aromatic hydrocarbons. I. Kinetic study of the thermal cracking of i-propylbenzene
}

\author{
Qi Chen * and Gilbert F. Froment *
}

Laboratorium voor Petrochemische Techniek, Rijksuniversiteit Gent, Krijgslaan 281, B-9000 Gent (Belgium)

(Received October 23, 1990; accepted November 28, 1990)

\begin{abstract}
Experiments on the thermal cracking of i-propylbenzene (cumene) were carried out in a bench scale tubular reactor under conditions as close as possible to those in industrial operations. The experimental unit is described and the results are presented. The free radical reaction network was established. The activation energy and frequency factor for each reaction step in the network were estimated, first by trial and error and then more systematically by a minimization technique. The thermodynamic analysis was conducted for the reversible reactions. This imposed constraints on the Arrhenius parameters. The yields of the products calculated by the kinetic model are in good agreement with the experimental observations.
\end{abstract}

Aromatic hydrocarbons; kinetic models; i-propylbenzene; pyrolysis; thermal cracking.

\section{INTRODUCTION}

Detailed kinetic models based upon free radical mechanisms are especially scarce for aromatics and olefins cracking. When heavier feedstocks like gasoil are considered, the understanding of the kinetic behaviour of aromatic cracking is a necessity. Understanding the secondary reactions of the main cracking products (olefins) is just as important.

In the present paper, detailed radical kinetic models for the thermal cracking of i-propylbenzene (cumene) are developed, together with reliable parameters for the elementary radical reactions involved in the cracking of the aromatics.

\footnotetext{
\ Present address: Dept. Chem. Eng., Eindhoven U. Tech., 5600 MB Eindhoven (The Netherlands).
} 


\section{EXPERIMENTAL STUDY}

\section{Experimental unit and procedure}

The setup used for the experiments of the thermal cracking of aromatics is a bench scale unit, shown schematically in Fig. 1 . The unit can be divided into the feed, reaction and analysis sections. The hydrocarbon and diluent water are pumped into the vaporizers. The water vaporizer is packed with porcelain pellets, and the hydrocarbon vaporizer with glass wool for a smooth evaporation. The hydrocarbon vapour is superheated to $250^{\circ} \mathrm{C}$, mixed with steam, and further heated. An internal standard, nitrogen, is injected at the inlet of the hydrocarbon vaporizer. The nitrogen flow is accurately measured and controlled by a thermal mass flow controller.

The reactor is a $1430 \mathrm{~mm}$ long, $4 \mathrm{~mm}$ internal diameter tube, made of chromium steel $(17 \% \mathrm{Cr}$, no nickel). There are fifteen thermocouples along the reactor, 8 inside and 7 on the external tube skin. The reactor is heated electrically and placed vertically in a cylindrical furnace. The preheat section and the reaction section are heated separately. To compensate the heat loss near the outlet of the reactor, an extra heater is placed at the bottom of the furnace, so that the temperature will only drop at the outlet of the reactor. The pressure in the reactor is controlled by a back pressure regulator downstream from the outlet of the reactor. The pressure drop over the reactor is negligible. The reactor effluent is cooled in a heat exchanger by means of circulating oil. Any possible solid particles or tar are caught in a cyclone downstream of the quench. The cyclone is followed by a condenser in which steam and heavy products are condensed. The condenser is kept in

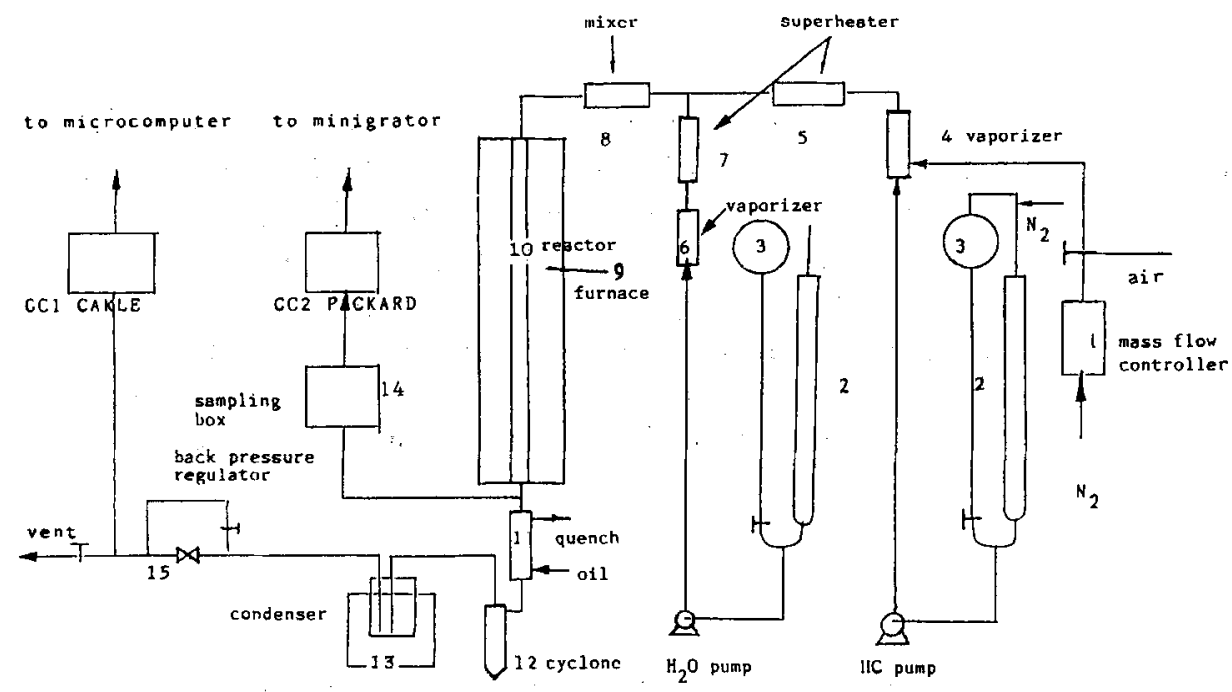

Fig. 1. Flow sheet of the experimental unit. 
a water bath to maintain a constant temperature, so that the $\mathrm{C}_{5}^{-}$fraction is not condensed.

The on-line analysis of the reactor effluent is performed by means of two gas chromatographs. A computerized GC CARLE 500 with three detectors, two thermal conductivity detectors (TCD) and one flame ionization detector (FID), analyses the light components including hydrogen, methane, oxygen, carbon monoxide, carbon dioxide, light hydrocarbons up to $\mathrm{C}_{4}$, and internal standard nitrogen, while the $\mathrm{C}_{5}^{+}$components are analyzed by a GC PACKARD model 724 with an FID. The Packard 724 is equipped with a fused silica capillary column with a length of $30 \mathrm{~m}$ and inner diameter 0.32 $\mathrm{mm}$. The column is coated with $0.25 \mu \mathrm{m}$ DB1 (polymethylsiloxane) as a stationary phase. It separates $C_{1}$ from $C_{2}$ at low temperatures, -30 or $-40^{\circ} \mathrm{C}$, and also the $\mathrm{C}_{5}^{+}$-components at higher temperatures.

A total effluent sample is taken on line by means of a hot gas sampling device at the reactor exit, before the oil cooler [1]. Since the $C_{2}, C_{3}$ and $C_{4}$ fractions are not separated on $\mathrm{DB} 1, \mathrm{a} \mathrm{C}_{4}^{-}$sample is withdrawn after the condenser and analysed on the CARLE 500. Reference to the internal standard allows the effluent composition to be cxpressed on an absolute basis. The identification of the peaks for the $\mathrm{C}_{4}^{-}$was performed by comparing the chromatograms with those of a calibration mixture. The $\mathrm{C}_{5}^{+}$products were identified by means of retention times and GC-MS.

Cumene was purchased from JANSSEN CHIMICA. The purity was 99\%, with about $1 \%$ aromatic impurities. The experiments were carried out under the conditions given in Table 1 .

\section{Data treatment and definitions}

In the present work, the responses of the $\mathrm{C}_{4}^{-}$and $\mathrm{C}_{5}^{+}$components on both GCs were calibrated prior to the cracking experiments. The procedure of the calibration is essentially the same as described by Dierickx et al. [2], and the results are similar.

The yield of a product is calculated from:

Yield of a product $=\frac{\text { flow rate of the product at exit }(\mathrm{g} / \mathrm{hr})}{\text { total hydrocarbon flow rate at inlet }(\mathrm{g} / \mathrm{hr})}$

\section{TABLE 1}

Reaction conditions for cumene cracking

\begin{tabular}{ll}
\hline Temperature at reactor outlet $\left({ }^{\circ} \mathrm{C}\right)$ & $610-730$ \\
Pressure (bar abs) & $1.3-1.8$ \\
Steam dilution $\left(\mathrm{kgH}_{2} \mathrm{O} / \mathrm{kgHC}\right)$ & $1 ; 2 ; 4$ \\
Feed flow rate $(\mathrm{gHC} / \mathrm{hr})$ & $12-34$
\end{tabular}


The accurately measured mass flow rate of nitrogen is used as an internal standard reference to calculate the flow rates of the components detected by the CARLE TCD: hydrogen, carbon monoxide, carbon dioxide, methane, ethylene, ethane and acetylene, from the ratios of peak areas:

$F_{i}^{\prime}(\mathrm{g} / \mathrm{hr})=\frac{\mathrm{CF}_{i} * \mathrm{PA}_{i}}{\mathrm{PA}_{r}} * F_{r}^{\prime}(\mathrm{g} / \mathrm{hr})$

where $\mathrm{CF}_{i}$ is the calibration factor for component $i$. Further, $\mathrm{PA}_{i}$ and $\mathrm{PA}_{r}$ represent the peak areas of component $i$ and of the reference, nitrogen, while $\mathrm{F}_{i}^{\prime}$ and $\mathrm{F}_{r}^{\prime}$ are the respective weight flow rates. From the TCD on the CARLE 500, the methane flow rate is known. It is used as a secondary standard in the above equation to quantify the flow rates of $\mathrm{C}_{3}$ and $\mathrm{C}_{4}$ which are detected by the FID of the CARLE 500. The flow rates of the $\mathrm{C}_{5}^{+}$ products are calculated from the peaks detected on the PACKARD 724. The sum of $C_{1}$ and $C_{2}$ is used as the reference component for this calculation instead of methane alone, since the yield of methane is too small. At very low conversion (corresponding to a $\mathrm{C}_{1}+\mathrm{C}_{2}$ weight yield of $2 \%$ only), when the yields of the $C_{1}+C_{2}$ are too low to serve as a reference, the normaliza-

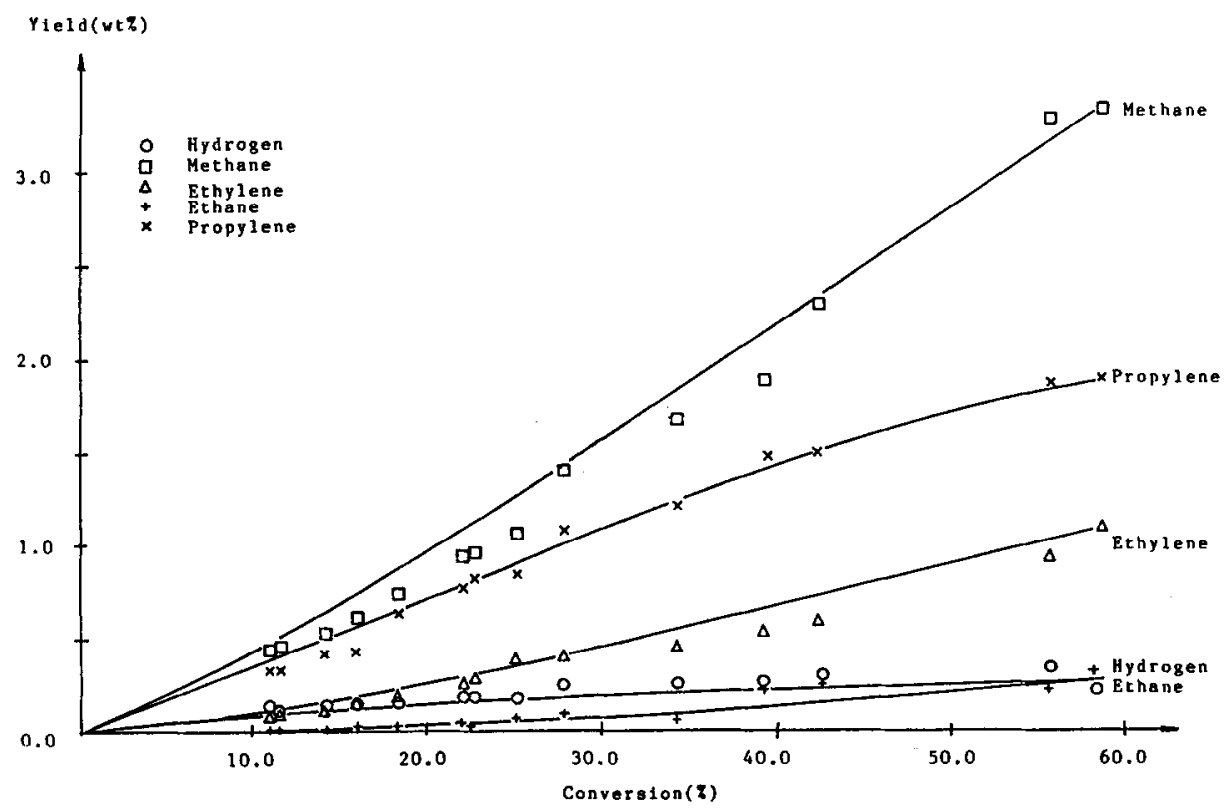

Fig. 2. The yield vs. conversion figures of the cumene cracking, comparison of experiments with simulation: $\delta=1 ; T=610-730^{\circ} \mathrm{C}$; Points, experiments; Lines, calculated by model. 
tion method is used for calculating the flow rates of the $\mathrm{C}_{5}^{+}$products according to the following equation:

$F_{i}^{\prime}(\mathrm{g} / \mathrm{hr})=\frac{\mathrm{CF}_{i} * \mathrm{PA}_{i}}{\sum \mathrm{CF}_{i} * \mathrm{PA}_{i}} *\left(\mathrm{~g} / \mathrm{hr}\right.$ feed $-\mathrm{g} / \mathrm{hr}$ sum of $\mathrm{C}_{4}^{-}$flow $)$

Mass balances were calculated, both overall and based on carbon and hydrogen respectively, over the feed hydrocarbons and the reactor effluent. For most runs, the mass balances were within the range of $95-105 \%$. Runs with $5 \%$ errors on the mass balances were rejected.

Results and discussion

The major products of the thermal cracking of cumene are hydrogen, methane, ethylene, ethane, propylene, propane, benzene, toluene, styrene, ethylbenzene and alpha-methylstyrene. Other products were $C_{9}$ isomers such as trans- and cis-beta-methylstyrene, allylbenzene, indane and indene. Minor amounts of $\mathrm{C}_{4}, \mathrm{C}_{10}$ and $\mathrm{C}_{11}$ were also observed at high conversions. The products having the highest yields were, of course, styrene and alpha-methylstyrene. The yields of some major products were plotted against conver-

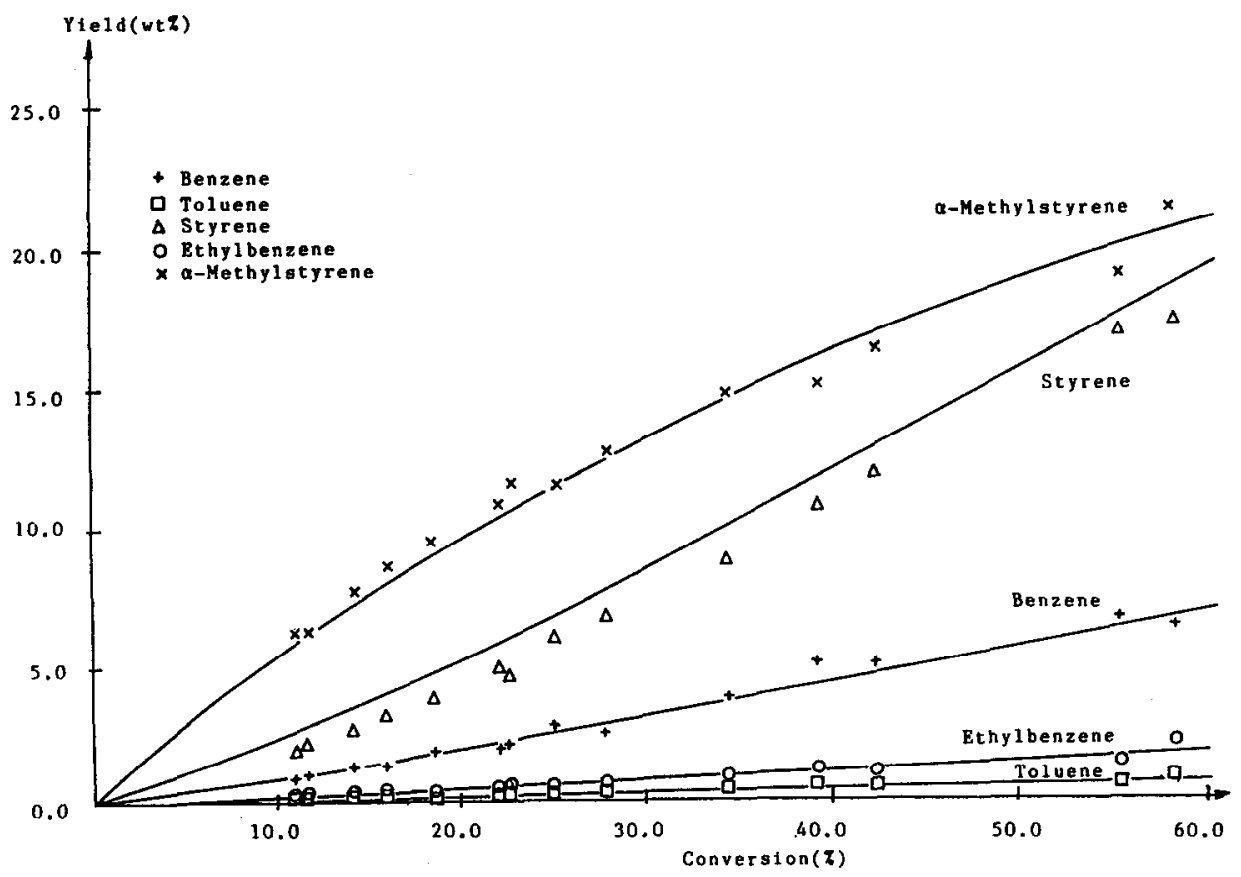

Fig. 3. The yield vs. conversion figures of the cumene cracking, comparison of experiments with simulation: $\delta=1 ; T=610-730^{\circ} \mathrm{C}$; Points, experiments; Lines, calculated by model. 


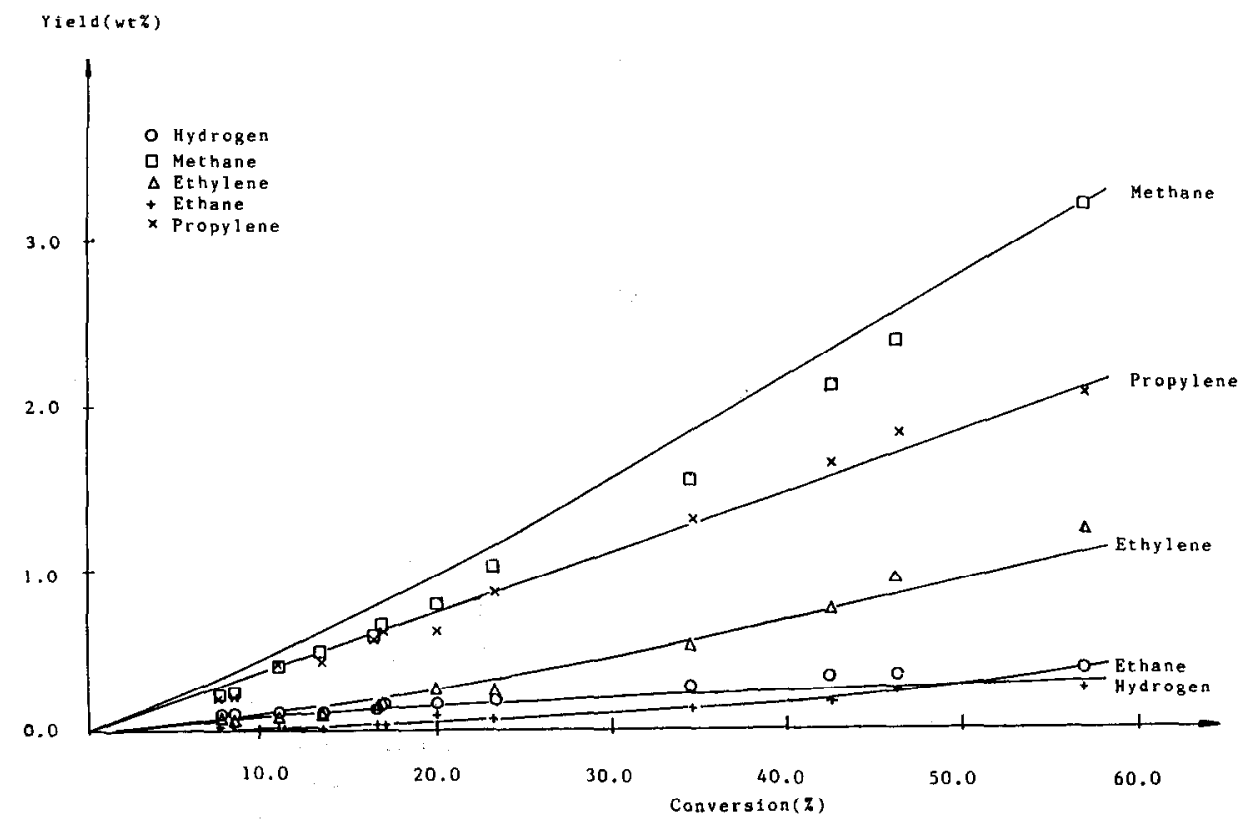

Fig. 4. The yield vs. conversion figures of the cumene cracking, comparison of experiments with simulation: $\delta=2 ; T=610-730^{\circ} \mathrm{C}$; Points, experiments; Lines, calculated by model.

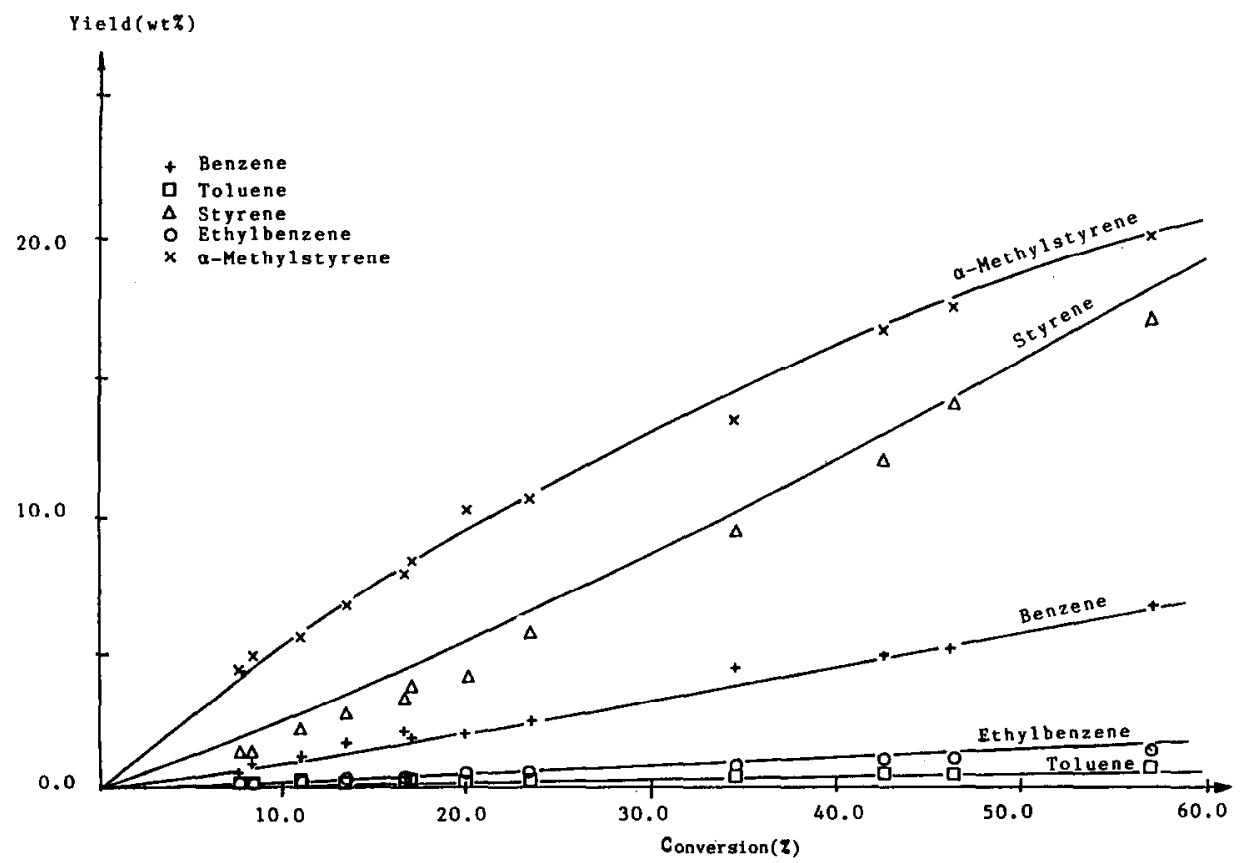

Fig. 5. The yield vs. conversion figures of the cumene cracking, comparison of experiments with simulation: $\delta=2 ; T=610-730^{\circ} \mathrm{C}$; Points, experiments; Lines, calculated by model. 
sion in Figs. 2-5. The points are the experimental yields, while the lines are calculated from the model, to be discussed later.

The product distribution of cumene cracking can be compared with that of i-butane, which has an analogous structure, except that methyl is replaced by phenyl. In the products of i-butane cracking, propylene and i-butene are major products, while the ethylene yields are rather low [3]. This is in agreement with the effluent composition of cumene cracking, provided that propylene corresponds to styrene and i-butene to alpha-methylstyrene. Ethylene must be formed by similar pathways. Also, hydrogen and methane are present in large amounts in both cases. They are associated with the production of alpha-methylstyrene and styrene in cumene cracking and i-butene and propylene in i-butane cracking. The overall product distribution of cumene cracking is much more complicated, because of the presence of the phenyl ring. When any one of the three methyl groups is split off from i-butane, the products are the same: $\mathrm{C}_{1}$ and $\mathrm{C}_{3}$ (molecules or radicals). In cumene, however, while splitting either of the two methyl groups gives identical products, the breaking of the third bond yields phenyl and propylene. The phenyl ring introduces more complications by the formation of other radicals such as benzyl, 1-phenylethyl, 2-phenylethyl, which are partly responsible for the formation of toluene, ethylbenzene and other aromatics.

\section{KINETIC MODELLING}

\section{Free radical reaction network}

The elementary free radical reaction steps were classified into the following six categories: initiation, hydrogen abstraction and substitution, radical decomposition, addition on olefins, isomerization of radicals and termination by recombination or disproportionation of radicals. Besides, some non-elementary reactions were also considered.

The reaction network was selected in the first place on the basis of the experimental product distribution. The bond dissociation energy (BDE), radical activity and thermochemistry were also important guidelines. In a later stage, the minimization of the objective function involved in the parameter estimation also led to the elimination of certain insignificant reactions or to the addition of more reactions.

Initiation was not limited to $\mathrm{C}-\mathrm{C}$ bond scission. The rupture of the $\mathrm{C}-\mathrm{H}$ bonds was also included, because the experimental results and the bond dissociation energy values prove that they are possible. In addition, the initiation reactions by the $\mathrm{C} \mathrm{H}$ bond scission are also reported in the literature [4,5].

The hydrogen abstracting radicals included the hydrogen atom, the methyl radical and the phenyl radical. The contributions to the hydrogen abstrac- 
tions by the ethyl, benzyl, and 1-phenylethyl radicals were found to be insignificant in the present conditions.

The abstraction of a tertiary hydrogen is much easier than that of a primary or secondary. In the present model the inclusion of the abstractions of the tertiary hydrogen is necessary, because a benzyl-like radical, namely, alpha-cumyl, is formed which leads to the formation of a very important product in the cumene cracking: alpha-methylstyrene.

Substitution reactions are reported to be important in aromatics cracking. The following two substitutions were included in the cumene cracking network (the numbering of the reactions refers to Table 2).

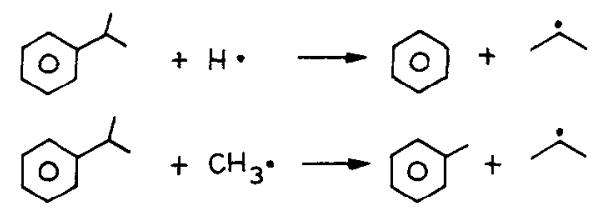

Additions on the major olefins, ethylene, propylene, styrene, and alphamethylstyrene of a hydrogen atom, methyl radical and phenyl group were accounted for.

To produce a sufficient amount of ethylene, the isomerization of i-propyl to $n$-propyl was added to the network. Although this isomerization was repeatedly proposed, it was evidenced by an isotopic pyrolysis of propane only in 1980 [6]. The argument whether this isomerization proceeds via an intermolecular pathway or an intramolecular one, however, was still not clarified. In the present network it was chosen to proceed via an intramolecular reaction.

The termination reactions usually involve radicals such as methyl, ethyl, which are present in high concentrations. Terminations by phenyl and benzylic radicals are also included.

Two disproportionations were added to the model to improve the simulation of the yields of ethylene and ethane.

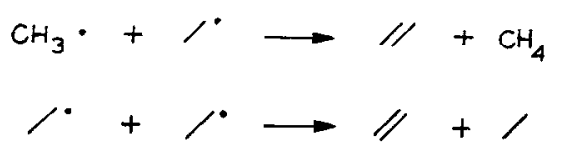

The model includes an important path which converts alpha-methylstyrene into styrene, i.e., the addition of hydrogen atoms on alpha-methylstyrene to form a beta-cumyl radical, which decomposes to give styrene. The scission of a methyl radical from alpha-methylstyrene was necessary to 


\section{TABLE 2}

Model for cumene cracking

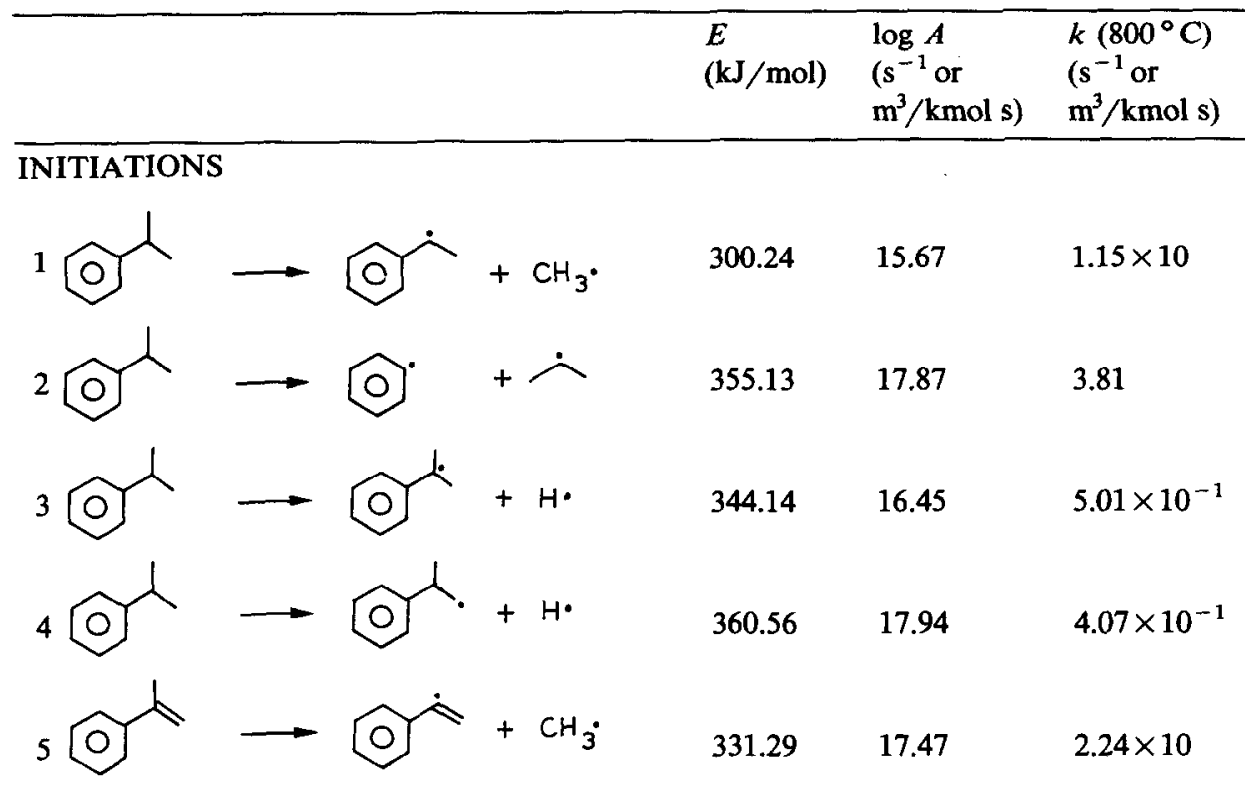

HYDROGEN ABSTRACTIONS

6 Oु $+\mathrm{H} \cdot \longrightarrow$ O

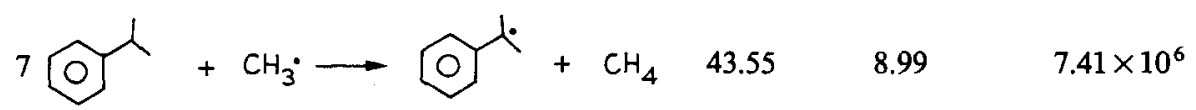

$8 \widehat{\mathrm{O}}+\widehat{\mathrm{O}} \rightarrow \widehat{\mathrm{O}}+\mathrm{O} 36.16 \quad 9.52 \quad 3.31 \times 10^{9}$

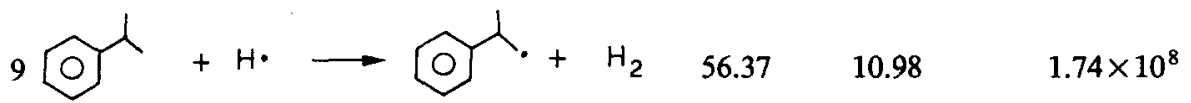

10 O $+\mathrm{CH}_{3} \longrightarrow \widehat{\mathrm{O}}+\mathrm{CH}_{4} \quad 64.56 \quad 9.49 \quad 2.24 \times 10^{6}$

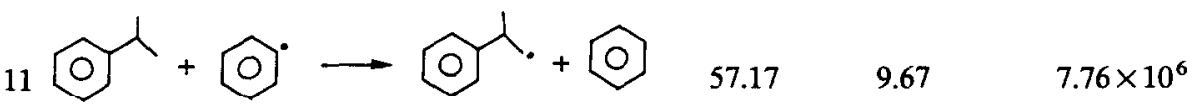

SUBSTITUTIONS

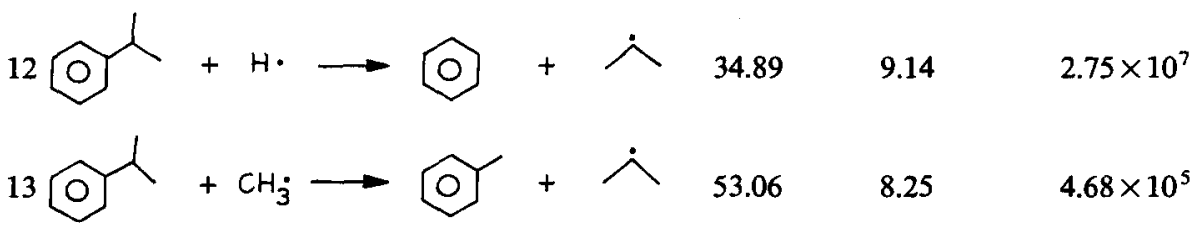


TABLE 2 (continued)

$\begin{array}{lll}E & \log A & k\left(800^{\circ} \mathrm{C}\right) \\ (\mathrm{kJ} / \mathrm{mol}) & \left(\mathrm{s}^{-1} \text { or }\right. & \left(\mathrm{s}^{-1} \text { or }\right. \\ & \left.\mathrm{m}^{3} / \mathrm{kmol} \mathrm{s}\right) & \left.\mathrm{m}^{3} / \mathrm{kmol} \mathrm{s}\right)\end{array}$

\section{RADICAL ADDITIONS}

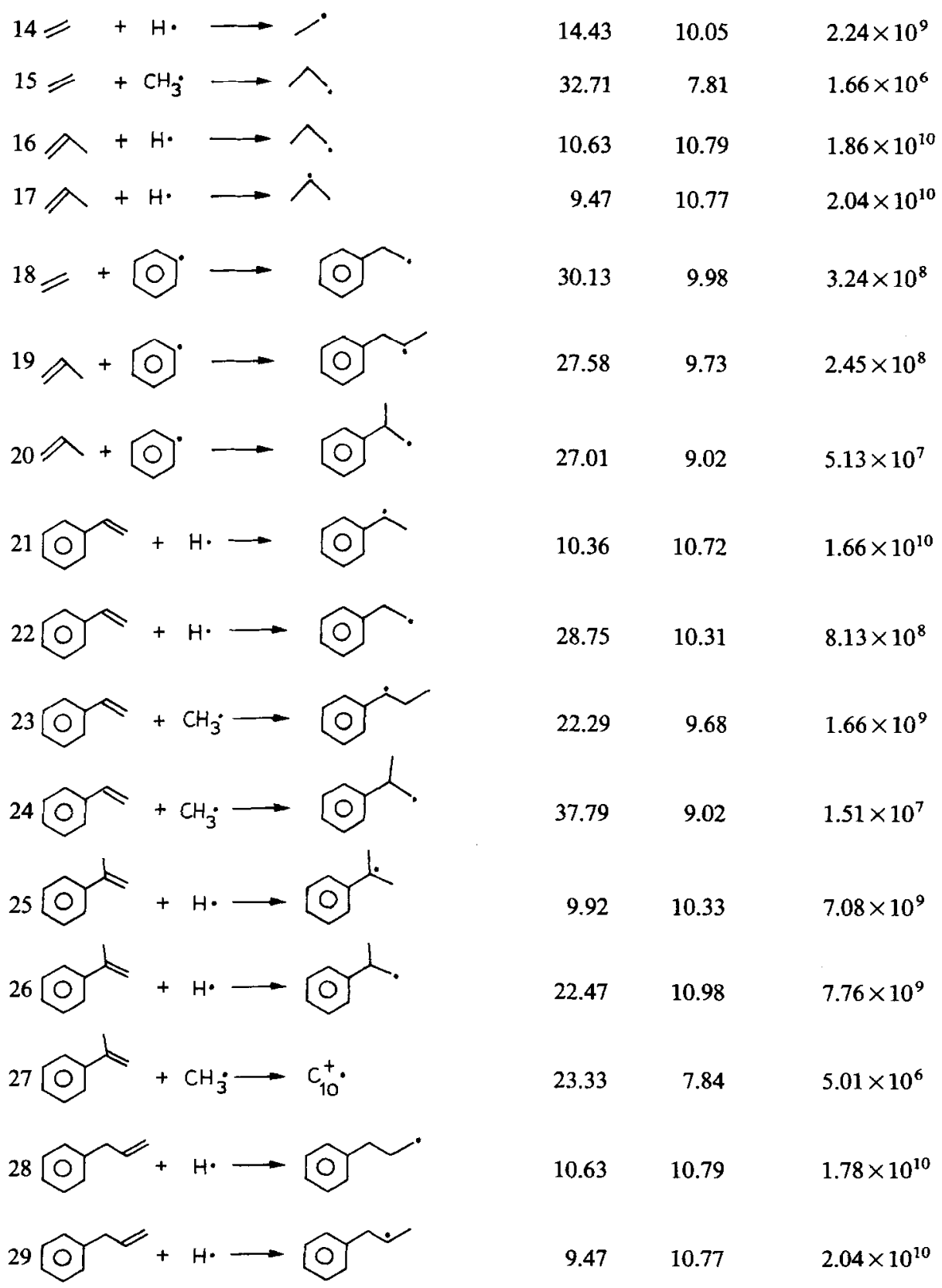




\begin{tabular}{|c|c|c|c|}
\hline & $\begin{array}{l}E \\
(\mathrm{~kJ} / \mathrm{mol})\end{array}$ & $\begin{array}{l}\log A \\
\left(\mathrm{~s}^{-1} \text { or }\right. \\
\left.\mathrm{m}^{3} / \mathrm{kmol} \mathrm{s}\right)\end{array}$ & $\begin{array}{l}k\left(800^{\circ} \mathrm{C}\right) \\
\left(\mathrm{s}^{-1} \text { or }\right. \\
\left.\mathrm{m}^{3} / \mathrm{kmol} \mathrm{s}\right)\end{array}$ \\
\hline$+\mathrm{H} \cdot$ & 10.57 & 10.72 & $1.62 \times 10^{10}$ \\
\hline 310 & 24.83 & 10.88 & $4.68 \times 10^{9}$ \\
\hline
\end{tabular}

\section{RADICAL DECOMPOSITIONS}

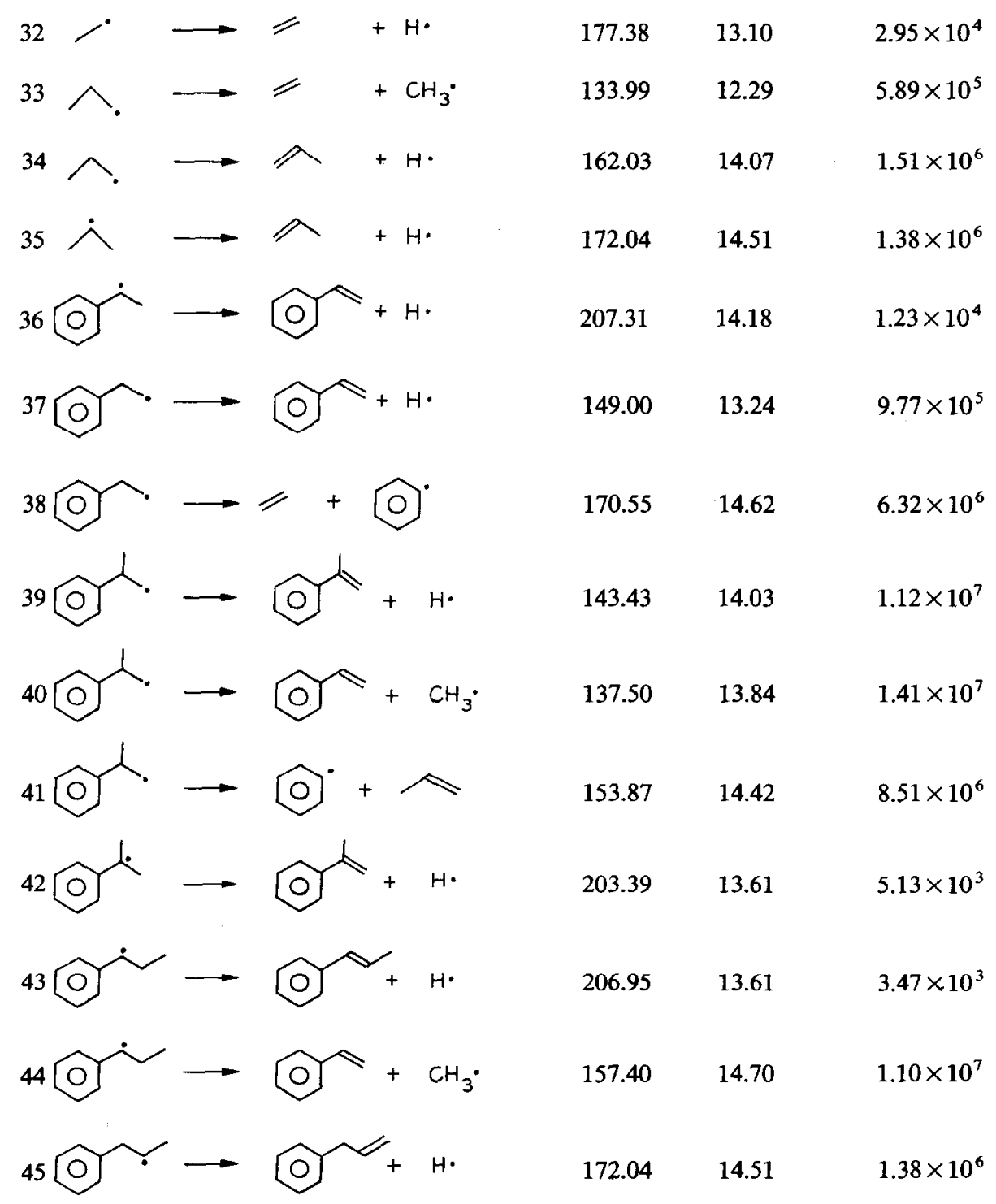


TABLE 2 (continued)

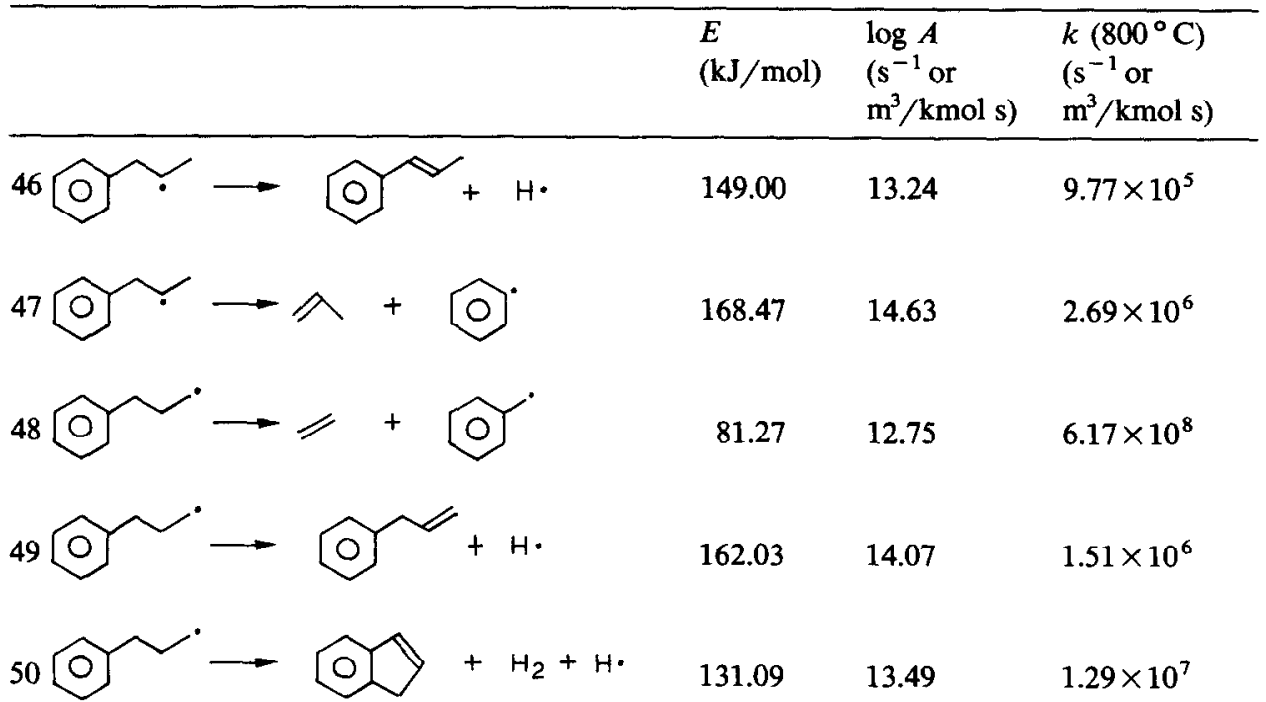

ISOMERIZATION

$51 \stackrel{\wedge}{\longrightarrow}$

$138.76 \quad 14.92$

$1.78 \times 10^{8}$

TERMINATIONS AND DISPROPORTIONATIONS

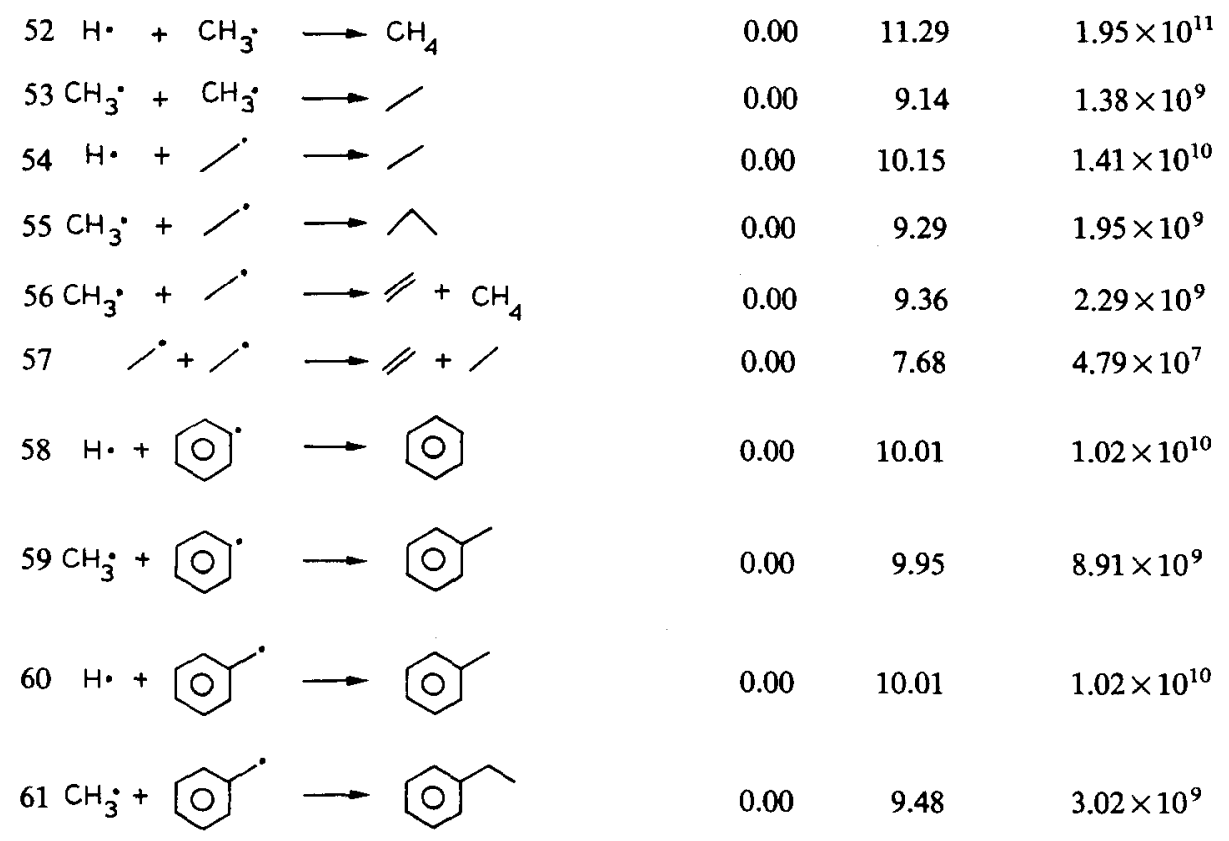


TABLE 2 (continued)

\begin{tabular}{|c|c|c|c|}
\hline & $\begin{array}{l}E \\
(\mathrm{~kJ} / \dot{\mathrm{mol}})\end{array}$ & $\begin{array}{l}\log A \\
\left(\mathrm{~s}^{-1} \text { or }\right. \\
\left.\mathrm{m}^{3} / \mathrm{kmols}\right)\end{array}$ & $\begin{array}{l}k\left(800^{\circ} \mathrm{C}\right) \\
\left(\mathrm{s}^{-1} \text { or }\right. \\
\left.\mathrm{m}^{3} / \mathrm{kmol} \mathrm{s}\right)\end{array}$ \\
\hline $62 \mathrm{H} \cdot+$ & 0.00 & 11.15 & $1.41 \times 10^{11}$ \\
\hline $63 \mathrm{CH}_{3}+$ & 0.00 & 9.52 & $3.31 \times 10^{9}$ \\
\hline $64 \mathrm{H} \cdot$ & 0.00 & 10.45 & $2.82 \times 10^{10}$ \\
\hline $65 \mathrm{CH}_{3}+$ & 0.00 & 8.81 & $6.46 \times 10^{10}$ \\
\hline $66 \mathrm{H} \cdot+$ & 0.00 & 11.29 & $1.95 \times 10^{11}$ \\
\hline $67 \mathrm{H}+\mathrm{C}_{10}^{+} \longrightarrow \mathrm{C}_{10}^{+}$ & 0.00 & 8.15 & $1.41 \times 10^{8}$ \\
\hline
\end{tabular}

improve the fit of the styrene yield. This path, breaking a bond with bond dissociation energy of about $350 \mathrm{~kJ} / \mathrm{mol}$,

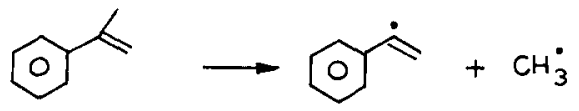

is energetically possible. Furthermore, phenylacetylene was identified from the GC-MS analysis when the cumene conversion was high. This provides experimental evidence for the existence of the styrenyl radical. Therefore, this reaction and the reactions terminating the styrenyl radical were included in the model. The decomposition of the styrenyl radical was excluded because its decomposition into phenylacetylene is negligibly small. The introduction of these three reactions considerably improved the simulation of the yields of styrene and alpha-methylstyrene, in particular at higher conversions.

\section{Thermodynamic constraints}

Thermodynamic properties of a substance place a strong quantitative constraint on the kinetic parameters of the reactions in which that substance participates. The introduction of the thermodynamic constraints not only makes the kinetic parameters more rigorous, but also reduces the number of 
independent parameters and therefore the computation time required for their estimation.

The constraints used here are the differences of activation energies and frequency factors between the forward and the backward reactions for the reversible reactions.

For a reversible gas phase reaction

$$
a \mathrm{~A}+b \mathrm{~B} \rightleftharpoons c \mathrm{C}+d \mathrm{D}
$$

if the reactions in both directions are elementary, the enthalpy and entropy of reaction are related to the Arrhenius parameters by the following equations,

$$
\begin{aligned}
& \Delta H^{0}=E_{p \mathrm{f}}-E_{p \mathrm{~b}} \\
& \Delta S^{0}=R \ln A_{p \mathrm{f}} / A_{p \mathrm{~b}}
\end{aligned}
$$

where $\Delta H^{0}$ and $\Delta S^{0}$ are the standard enthalpy and entropy changes of the reaction respectively; $E$ is the activation energy and $A$ the frequency factor of the reaction. All the entities are at the 1.013 bar ideal gas standard which is denoted by the superscript 0 . Subscripts $p$, $\mathrm{f}$, and b stand for "pressure", "forward", and "backward" respectively.

In the kinetic study of thermal cracking reactions, the concentration standard is used instead of pressure. Introducing the relations between the two standards into eqns. (4) and (5) and applying them to the most important reversible reactions in the present model, the additions on olefins and radical decompositions, the following relations are obtained:

$$
\Delta E_{\mathrm{bf}}=E_{c \mathrm{~b}}-E_{c \mathrm{f}}=-\Delta H^{0}-R T
$$

$\Delta \log A_{\mathrm{bf}}=\log A_{\mathrm{cb}}-\log A_{\mathrm{cf}}=-\frac{\Delta S^{0}}{2.303 R}-\frac{1+\ln R^{\prime} T}{2.303}$

where $R$ and $R^{\prime}$ are the gas constant in different units, $8.314 \mathrm{~kJ} / \mathrm{mol} \mathrm{K}$ and 0.08314 bar liter $/ \mathrm{mol} \mathrm{K}$, respectively.

The remaining problem, then, is to find the enthalpy and entropy change of the reaction. They can be calculated by the algebraic sum of the heats of formation $\Delta H_{\mathrm{f}}^{0}$ and standard entropies $S^{0}$ of the participating species. The heat of formation and standard entropy of a molecule can be found in physicochemistry handbooks, whereas those of the radical species must be estimated. Benson's group additivity method [7] was used here to estimate the properties of the radicals.

The above calculations refer to a temperature of $298 \mathrm{~K}$. To calculate the $\Delta E_{\mathrm{bf}}$ and $\Delta \log A_{\mathrm{bf}}$ at higher temperatures, $1000 \mathrm{~K}$, for example, requires the data of temperature dependence of heat capacities. The heat capacity, $C_{p}^{0}$, of a molecule and radical can also be computed by the group additivity method using the data given by Benson [7]. Although the heat capacities of species (molecule and radical) are rather large, the $\Delta C_{p}^{0}$ of a free radical 
reaction is generally small because of the cancellation effect of reactants and products.

The resulting $\Delta \log A_{\mathrm{bf}}$ and $\Delta E_{\mathrm{bf}}$ for all the reversible reaction pairs in the networks was later adjusted. The final values after the adjustment are listed in Table 3.

\section{Parameter estimation}

The parameters in the kinetic model can be estimated from the minimization of the following objective function:

$S(b)=\sum_{j}^{v} \sigma_{i i} \sum_{k}^{n}\left[y_{k, i}-f\left(x_{k}, b\right)\right]^{2}$

when the errors are normally distributed with zero mean and those associated with the $j$ th and $i$ th responses are uncorrelated. In eqn. (8), $f\left(x_{k}, b\right)$ are the calculated yields of the products by means of the kinetic model with the present choice of the parameters, $b$, and $v$ represents the number of responses and $n$ the number of experiments.

$\sigma_{i i}$ are the elements of the inverse of the diagonal error covariance matrix of the experimental errors within an experiment, $\sum$. In this study, however, weighting factors, $\alpha_{i}$, are used in eqn. (8) to replace $\sigma_{i i}$, which equilibrate the contributions of the different yields in $S(b)$. They are defined as:

$\alpha_{i}=\frac{\left(\sum_{j=1}^{n} y_{i j}\right)^{-a}}{\sum_{i=1}^{v}\left(\sum_{j=1}^{n} y_{i j}\right)^{-a}}$

For $a=1$, the weighting factors express the real relative importances of the components, whilst for $a=0$, all the components are weighted equally. A reasonable compromise value is $0.1-0.3$.

To minimize the objective function $S(b)$ in eqn. (8), a derivative free Rosenbrock algorithm [8,9] was applied in this study.

The calculated yields were obtained by integration of the set of continuity equations. The temperature profile of the process gas was measured and introduced into the differential equations.

It is assumed that the flow pattern in the reactor is of the plug flow type and that there is no radial temperature or concentration gradient. With these assumptions, the continuity equation for component $j$ at the steady state is as follows:

$$
\frac{\mathrm{d} F_{j}}{\mathrm{~d} z}=\frac{-\pi d_{t}^{2}}{4} \sum_{i} n_{i j} r_{i}
$$


TABLE 3

Thermodynamic constraints

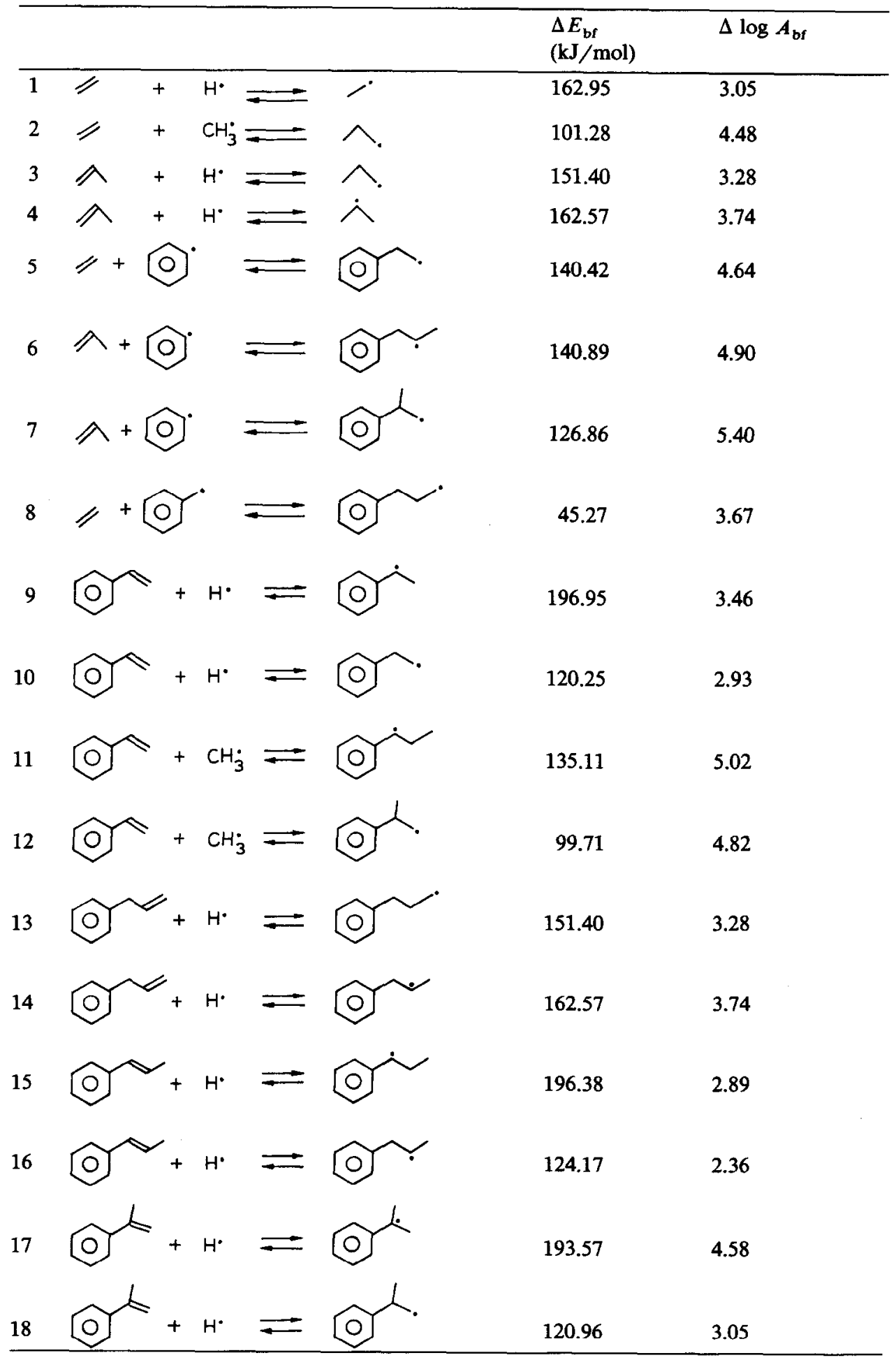


with $F_{j}=$ molar flow of the $j$ th component $(\mathrm{kmol} / \mathrm{s}) ; z=$ length along the reactor $(\mathrm{m}) ; d_{t}=$ coil inner diameter $(\mathrm{m}) ; n_{i j}=$ stoichiometric coefficient of the $j$ th component in the $i$ th reaction (negative for a reactant and positive for a product); and $r_{i}=$ reaction rate of the $i$ th reaction $\left(\mathrm{kmol} / \mathrm{m}^{3} \mathrm{~s}\right)$.

For the integration of the continuity equations, which are a set of stiff ordinary differential equations, Dente's routine was employed with some modifications $[10,11]$. This routine was implemented in the thermal cracking program of the Laboratorium voor Petrochemische Techniek.

With the model containing 67 reactions, 118 Arrhenius parameters were to be determined, i.e. 51 activation energies and 67 frequency factors. The network comprised addition-decomposition pairs shown in Table 3. Only the parameters of addition reactions needed to be estimated, whereas those for the decompositions were determined from the $\Delta E_{\mathrm{bf}}$ and $\Delta \log A_{\mathrm{bf}}$ and the parameters for additions. Hence, the number of parameters to be determined was decreased by 34 , from 118 to 84 .

The initial guesses of the parameters were chosen within Benson's ranges as in Table 4. The compilations of parameters by Allara and Shaw [12] and Isbarn [13] were also important references.

The parameters of the substitution reactions were supposed to be in the range of the addition of a radical on an olefin. The reason for this is that the substitution of a group of an aromatic side chain proceeds via addition of a radical on the ring and the decomposition of the added intermediate, and the decomposition is so fast that the addition is the rate controlling step. For the hydrogen abstractions, the contribution approach was applied to some extent to decrease the number of parameters. This approach has been described in detail by Willems and Froment [14]. Abstraction of a primary hydrogen atom from a cumene molecule by hydrogen atom,

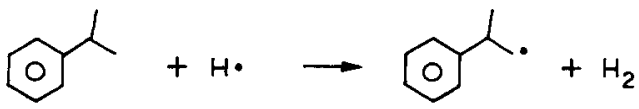

was taken as a reference. Its parameters, $E_{\mathrm{R} 1}$ and $\log A_{\mathrm{R} 1}$, were denoted as $E_{\mathrm{Ab}}\left(\mathrm{H}_{p}\right)$ and $\log A_{\mathrm{Ab}}\left(\mathrm{H}_{p}\right)$ by Willems and Froment [14].

TABLE 4

Limits of $E$ and $A$ [Benson, 1976]

\begin{tabular}{lll}
\hline Reaction & $E(\mathrm{~kJ} / \mathrm{mol})$ & $\log A$ \\
\hline Initiation & varying & $16 \pm 1$ \\
H-abstraction & $32 \pm 8$ & $8.5 \pm 1$ \\
Addition & $0-32$ & $9 \pm 1$ \\
Termination & 0 & $9.5 \pm 1$ \\
\hline
\end{tabular}


The parameters of the abstraction of a tertiary hydrogen by a hydrogen atom

$\widehat{\mathrm{O}}+\mathrm{H} \cdot \widehat{\mathrm{O}}+\mathrm{H}_{2}$

are then

$$
\begin{aligned}
& E_{6}=E_{\mathrm{R} 1}+\Delta E_{1}=E_{\mathrm{R} 1}+\Delta E_{\mathrm{Ab}}(\alpha)_{\mathrm{ar}}+\Delta E_{\mathrm{Ab}}(\mathrm{t}) \\
& \begin{aligned}
\log A_{6} & =\log A_{\mathrm{R} 1}+\Delta \log A_{1} \\
& =\log A_{\mathrm{R} 1}+\Delta \log A_{\mathrm{Ab}}(\alpha)_{\mathrm{ar}}+\Delta \log A_{\mathrm{Ab}}(\mathrm{t})
\end{aligned}
\end{aligned}
$$

in which $\Delta E_{1}$ and $\Delta \log A_{1}$ are the sum of the contribution of the difference in position of hydrogen atoms with respect to the benzene ring ( $\alpha$ for the tertiary hydrogens, and $\beta$ for primary), $\Delta E_{\mathrm{Ab}}(\alpha)_{\mathrm{ar}}, \Delta \log A_{\mathrm{Ab}}(\alpha)_{\mathrm{ar}}$ and the contribution of the difference in the order of the $\mathrm{H}$ atoms (primary or tertiary), $\Delta E_{\mathrm{Ab}}(\mathrm{t}), \Delta \log A_{\mathrm{Ab}}(\mathrm{t})$. In the parameter estimation, these two contributions were not separated, but given as a single value, $\Delta E_{1}$ and $\Delta \log$ $A_{1}$. The abstraction of hydrogen by methyl radicals and phenyl radicals were dealt with in the same way.

The minimization used 16 molecular species as responses in the objective function, i.e. hydrogen, methane, ethylene, ethane, propylene, propane, benzene, toluene, styrene, ethylbenzene, alpha-methylstyrene, beta-methylstyrene, indene, allylbenzene, cumene and $\mathrm{C}_{10}^{+}$. Eighteen experimental runs were used which covered the temperature range $610-730^{\circ} \mathrm{C}$. Runs with steam dilutions $1 \mathrm{~kg} / \mathrm{kg}$ and $2 \mathrm{~kg} / \mathrm{kg}$ were equally selected. The conversion varied from $7 \%$ to $60 \%$.

The final parameter estimates are listed in Table 2.

\section{Comparison of experimental and calculated results}

The calculated product distributions, using the model of Table 2, are compared with the experimental ones in Figs. 2-5. The agreement is excellent over the whole conversion range and for all the products.

\section{Discussion of the parameter estimates}

The final parameter estimates fall within reasonable ranges. Most of them fall between Benson's limits, except for the frequency factors for initiation reactions which exceed Benson's upper limit: $\log A=17$. In the literature, however, such large values are frequently reported. In fact, 35\% of the $\log A$ of initiation reactions are higher than 17 in Isbarn's compilation [13] of the kinetic parameters for the elementary reactions in the thermal cracking process. 
Robaugh and Stein [15] reported the Arrhenius parameters for the first initiation reaction, (1), as $E=298 \mathrm{~kJ} / \mathrm{mol}$ and $\log A=15.8$. The following values were also reported for the parameters: $E=255 \mathrm{~kJ} / \mathrm{mol}$ and $\log$ $A=13.3$ [16], and $E=276 \mathrm{~kJ} / \mathrm{mol}$ and $\log A=14.3$ [17]. The parameters obtained in this work, $E=300.24 \mathrm{~kJ} / \mathrm{mol}$ and $\log A=15.67$, agree better with those of Robaugh and Stein.

The parameters of the decomposition reactions, obtained by adding the parameters of additions and the $\Delta E_{\mathrm{bf}}$ and $\Delta \log A_{\mathrm{bf}}$, also fall within the expected range. High activation energies, around $200 \mathrm{~kJ} / \mathrm{mol}$, were found for reactions (36), (42) and (43), in which the decomposing radicals have a free electron in alpha position with respect to the phenyl ring and split off a hydrogen atom in the reaction. In the literature, such high values for this type of reaction have been reported by more than one author. The only one, however, who reported the parameters for this very reaction is Gavalas [18]. For the analogous reaction of an olefin, i.e.

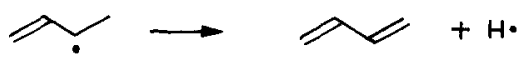

Isbarn [1981] collected two sets of parameters for this reaction in his compilation of Arrhenius parameters, reported by Allara and Shaw [12] and by Kunugi et al. [19]. Willems and Froment [14] have also estimated parameters for this reaction, and for isoprene formation as well, (ii):

$\nabla \rightarrow$ P $\rightarrow$ H.

These parameters and the corresponding rate coefficients are summarized in Table 5.

Furthermore, thermochemical calculations support these high activation energies. Indeed, the difference in activation energies for these decompositions and their reverse additions are already $211 \mathrm{~kJ} / \mathrm{mol}$ for reaction (36),

\section{TABLE 5}

Parameters for diene formation

\begin{tabular}{llrll}
\hline$E(\mathrm{~kJ} / \mathrm{mol})$ & $\log A(1 / \mathrm{s})$ & $k(1 / \mathrm{s})^{*}$ & Reaction & Reference \\
\hline 206.27 & 14.1 & $3.73 \times 10^{3}$ & (i) & Allara and Shaw [12] \\
196.65 & 13.7 & $4.60 \times 10^{3}$ & $(\mathrm{i})$ & Kunugi et al. [19] \\
216.31 & 15.1 & $11.45 \times 10^{3}$ & $(36)$ & Gavalas [18] \\
214 & 13.79 & $0.74 \times 10^{3}$ & (i) & Willems and Froment [14] \\
219 & 14.06 & $0.76 \times 10^{3}$ & (ii) & Willems and Froment [14] \\
207.31 & 14.18 & $3.96 \times 10^{3}$ & $(36)$ & This work \\
203.39 & 13.61 & $1.69 \times 10^{3}$ & $(42)$ & This work \\
206.95 & 13.61 & $1.11 \times 10^{3}$ & $(43)$ & This work \\
\hline
\end{tabular}

* Rate constant at $750^{\circ} \mathrm{C}$ 
216 for (42), 198 for (43), 200 for (i) and 213 for (ii). The rate constants for the decomposition of the alpha radicals are different from those of the decompositions of the paraffinic radicals, which are two orders of magnitude higher. Typically, the decomposition of $n$-propyl to give a propylene and a hydrogen atom has a rate constant $k(1 / \mathrm{s})=6.30 \times 10^{5}$ at $750^{\circ} \mathrm{C}$ from reaction (34), compared to $1.11 \times 10^{3}$ for reaction (43). This slowing down of the decomposition reaction by the presence of the phenyl ring can be attributed to the stable structure of the alpha-radicals.

Opposite to this is the lower activation energy for the decomposition of the beta-radicals to form conjugated olefins, i.e., reactions (37), (39) and (46), which coupled with the lower frequency factors accelerates the decomposition. These reactions have activation energies in the range of 140-150 $\mathrm{kJ} / \mathrm{mol}$, whereas the activation energies of the decompositions of the corresponding radicals without the phenyl ring, the paraffinic radicals, would be in the range of $160-180 \mathrm{~kJ} / \mathrm{mol}$. The higher reactivity of this type of radicals is attributed to the fact that the presence of the phenyl ring weakens the $\mathrm{C}-\mathrm{H}$ bonds in the beta-position with respect to the ring.

\section{Comparison of cumene cracking with paraffin cracking and further mechanistic considerations}

Although the detailed kinetic modeling based on the free radical mechanism is the current status of the thermal cracking modeling, the global kinetic studies of the early years may still be helpful in giving some ideas of the disappearance rate of the feedstock. For the cracking of $i$-butane and $n$-butane, Froment et al. [3] obtained activation energies and frequency factors varying slightly with the partial pressures of the butanes. The first order global kinetics, with $E=206.9 \mathrm{~kJ} / \mathrm{mol}$ and $\log A=10.94$, yield a rate constant of i-butane disappearance $k=0.681 / \mathrm{s}$ at $700^{\circ} \mathrm{C}$. At the same temperature, cumene disappears with $k=5.09$, using $E=207.9 \mathrm{~kJ} / \mathrm{mol}$ and $\log A=11.867$, as obtained from the present experiments. This is more than 7 times faster than i-butane. Obviously, the presence of the phenyl ring has made the side chain of the substituted aromatics crack faster than paraffins in the pyrolysis reactions.

The enhancement of the cracking rate by the phenyl ring can also be seen by the comparison of the reaction rates of cumene initiations with those of $\mathrm{i}$-butane. The rate constant for the first initiation reaction of cumene cracking, the most important one as well, is $0.3601 / \mathrm{s}$ at $700^{\circ} \mathrm{C}$. Literature values for this reaction are 0.307 [17], 0.412 [16] and 0.641 [15].

The parameters and rate constants of the corresponding initiation in i-butane cracking, yielding a methyl and an i-propyl radical, are summarized in Table 6. The parameters reported by different authors agree well. The activation energies are approximately $50 \mathrm{~kJ} / \mathrm{mol}$ higher than that of the most important initiation in the cumene cracking, reaction (1). An average 
TABLE 6

Parameters for i-butane initiation

\begin{tabular}{llll}
\hline$E(\mathrm{~kJ} / \mathrm{mol})$ & $\log A(\mathrm{l} / \mathrm{s})$ & $k_{700}(1 / \mathrm{s})$ & Reference \\
\hline 342 & 16.8 & 0.0279 & Konar et al. [20] \\
352 & 17.7 & 0.0644 & Allara and Shaw [12] \\
349 & 17.3 & 0.0371 & Allara and Shaw [12] \\
344 & 16.82 & 0.0228 & Willems and Froment [14] \\
\hline
\end{tabular}

value of the rate constant, $k_{700}$, over the four is 0.0381 . The cumene initiation is 11 times faster, close to the difference of the global disappearance rates.

The cracking of cumene yields more alpha-methylstyrene than styrene. This has been accounted for in the model, and can be explained as follows.

In cumene cracking, alpha-methylstyrene is produced through reactions (39) and (42):<smiles>CC(C)=Cc1ccc(C(C)=CC=Cc2ccccc2)cc1</smiles>

Styrene is produced through the following four reactions:

$$
\begin{aligned}
& \text { Or } \rightarrow \widehat{O}+H \text {. } \\
& \text { OC. } \rightarrow \widehat{O}+H^{\circ} \\
& \text { OH. } \rightarrow \widehat{O}+\mathrm{CH}_{3} \text {. } \\
& \hat{\mathrm{O}} \rightarrow \widehat{\mathrm{O}}+\mathrm{CH}_{3} \text {. }
\end{aligned}
$$

The contribution of reaction (36) is weak, since the reacting radical is generated by either addition or initiation. Reaction (37) does not contribute very much either, since the 2 -phenylethyl radical is formed via additions. In reaction (44), 1-phenylpropyl is again derived from styrene itself by an addition reaction. This leaves reaction (40) as the most important path for styrene formation, and beta-cumyl which is generated by hydrogen abstractions as the most important source.

In the model, either of the two reactions producing alpha-methylstyrene, (39), (42), can compete with reaction (40). Indeed, the rate constant of 
reaction (39), $3.45 \times 10^{6} 1 / \mathrm{s}$ at $1000 \mathrm{~K}$, is close to that of reaction (40), $4.54 \times 10^{6} 1 / \mathrm{s}$. Though the rate constant of (42) is smaller, the concentration of the alpha-cumyl radical is high, since the hydrogen abstraction reactions forming this radical proceed more rapidly than those forming beta-cumyl. Therefore, at low conversion at least, alpha-methylstyrene will be favored with respect to styrene. Of course, this is the case at low conversions. At high conversions, the picture is more complicated, due to the interconversions between styrene and alpha-methylstyrene.

\section{ACKNOWLEDGEMENT}

Q. Chen is grateful to the Chinese Government and the Belgian "Commissariaat-Generaal voor de Internationale Culturele Samenwerking" of the Flemish Community for financial support.

\section{NOMENCLATURE}

a power number in the relation for calculating the weighting factor in objective function

A, B, C, D reaction component

$A$ frequency factor, 1 st order reaction

$(1 / s)$

frequency factor, 2 nd order reaction

$\Delta A_{\mathrm{bf}} \quad$ ratio of frequency factors of backward and

$\left(\mathrm{m}^{3} / \mathrm{kmol} \mathrm{s}\right)$

forward reactions

$b \quad$ parameter vector

$C_{p}^{0} \quad$ specific heat of a species

$\Delta C_{p}^{0} \quad$ specific heat of a reaction

$(\mathrm{kJ} / \mathrm{kg} \mathrm{K})$

calibration factor

$\mathrm{CF}$

cross sectional diameter of internal reactor

tube

$(\mathrm{kJ} / \mathrm{kg} \mathrm{K})$

$d_{\mathrm{t}}$

$E \quad$ activation energy

$\Delta E_{\mathrm{bf}} \quad$ difference of activation energy of backward and forward reactions

$F_{i}^{\prime} \quad$ weight flow rate of component $i$

$F_{j} \quad$ molar flow rate of component $j$

(m)

$(\mathrm{k.I} / \mathrm{mol})$

$\Delta H_{\mathrm{f}}^{0} \quad$ heat of formation of component $i$

$n$ number of experiments

stoichiometric coefficient of the $j$ th component in the $i$ th reaction (negative

$n_{i, j}$ for a reactant and positive for a product)

PA peak area

$R \quad$ gas constant, 8.314

$(\mathrm{kJ} / \mathrm{kmol})$

$(\mathrm{kJ} / \mathrm{kmol} \mathrm{K})$ 


$\begin{array}{lll}R^{\prime} & \text { gas constant, } 0.08314 & \left(\mathrm{~m}^{3} \mathrm{bar} / \mathrm{kmol} \mathrm{K}\right) \\ S & \text { objective function } & \\ S^{0} & \text { standard entropy of a compound } & (\mathrm{kJ} / \mathrm{kmol} \mathrm{K}) \\ \Delta S^{0} & \text { entropy of reaction } & (\mathrm{kJ} / \mathrm{kmol} \mathrm{K}) \\ v & \text { number of responses } & \\ x_{k} & \begin{array}{l}\text { vector of independent variables } \\ y_{k j}\end{array} & \begin{array}{l}\text { calculated values of response } j \text { in the } \\ \text { objective function }\end{array} \\ z & \text { length along the reactor } & (\mathrm{m})\end{array}$

Greek Symbols

$\begin{array}{lll}\alpha_{i} & \text { weighting factor of } i \text { th response } & \\ \theta & \text { steam dilution } & \left(\mathrm{kg} \mathrm{H}_{2} \mathrm{O} / \mathrm{kg} \mathrm{HC}\right) \\ \sigma_{i i} & \text { element of inverse error covariance matrix }\end{array}$

\section{Subscripts}

$\begin{array}{ll}\text { b } & \text { backward } \\ \text { bf } & \text { difference between backward and forward } \\ c & \text { concentration } \\ \text { f } & \text { forward } \\ p & \text { pressure } \\ \text { r } & \text { reference } \\ \text { t } & \text { tube }\end{array}$

Superscripts

0

ideal gas standard

\section{REFERENCES}

1 P.S. Van Damme, C.E. Van Camp, P.J. Clymans and G.F. Froment, Hot on-line sampling improves reactor control, Oil \& Gas J., Sept. 7 (1981) 124.

2 J.L. Dierickx, P.M. Plehiers and G.F. Froment, On-line gas chromatographic analysis of hydrocarbon effluents. Calibration factors and their correlation, J. Chromatogr., 362 (1986) 155.

3 G.F. Froment, B.O. Van de Steene, P.J. Van den Berghe and A.G. Goossens, Thermal cracking of light hydrocarbons and their mixtures, AIChE J., 23 (1977) 93-106.

4 T. Kunugi, K. Soma and T. Sakai, Thermal reaction of propylene. Mechanism, Ind. Eng. Chem. Fundam., 9 (1970) 319.

5 N. Sankaran, Thermal Cracking of Cyclohexane and Methylcyclopentane. An experimental and modeling study, Ph.D. Thesis, Gent, 1982.

6 L. Szirovicza and L. Szilagyi, Thermal decomposition of 2,2-propane-d $\mathrm{d}_{2} \cdot \mathrm{CH}_{3} \mathrm{CDCH}_{3}$ radical isomerization, Int. J. Chem. Kinet., 12 (1980) 113. 
7 S.W. Benson, Thermochemical Kinetics, 2nd edn., Wiley, New York, 1976.

8 H.H. Rosenbrock, An automatic method for finding the greatest or least value of a function, Comput. J., 3 (1961) 175-184.

9 H.H. Rosenbrock and C. Story, Computational Techniques for Chemical Engineers, Pergamon, Oxford, 1966.

10 M. Dente, E. Ranzi and A.G. Goossens, Detailed prediction of olefin yields from hydrocarbon pyrolysis through a fundamental simulation model (SPYRO), Comput. Chem. Eng., 3 (1979) 61-75.

11 P. Clymans, The Production of Olefins from Gasoil and the Rigorous Simulation of the Thermal Cracking, Ph.D. Thesis, Gent, 1982.

12 D.L. Allara and R. Shaw, A compilation of kinetic parameters for the thermal degradation of $n$-alkane molecules, J. Phys. Chem. Ref. Data, 9 (1980) 523.

13 G. Isbarn, Compilation of Elementary Reactions Involved in Hydrocarbon Pyrolysis, Technical Report No. 1, Heidelberg, 1981.

14 P. Willems and G.F. Froment, Ind. Eng. Chem. Res. 27 (1988) 1959-1971.

15 D.A. Robaugh and S.E. Stein, Very low pressure pyrolysis of ethylbenzene, isopropylbenzene, and tert-butylbenzene, Int. J. Chem. Kinet., 13 (1981) 445-462.

16 C.H. Leigh and M. Szwarc, Pyrolysis of cumene, tert-butylbenzene, and p-cymene and the relevant bond dissociation energies, J. Chem. Phys., 20 (1952) 844.

17 J.A. Kerr, A.F. Trotman-Dickenson and M. Wolter, Pyrolysis of NN-dimethylaniline, cumene, and phenylhydrazine, and bond strengths in aromatic amino-compounds, $\mathrm{J}$. Chem. Soc. (1964) 3584.

18 G.R. Gavalas, Coal Pyrolysis, Elsevier, Amsterdam, 1982.

19 T. Kunugi, T. Sakai, K. Soma and Y. Sasaki, Kinetics and mechanism of the thermal reaction of ethylene, Ind. Eng. Chem., Fundam., 8, 3 (1969) 374.

20 R.S. Konar, R.M. Marshall and J.H. Purnell, The self-inhibited pyrolysis of isobutene, Int. J. Chem. Kinet., 5 (1973) 1007.

21 D.L. Allara and D. Edelson, A computational modeling study of the low-temperature pyrolysis of n-alkane; mechanisms of propane, n-butane and n-pentane pyrolysis, Int. J. Chem. Kinet., 7 (1975) 479.

22 K.H. Ebert, H.J. Ederer and P.S. Schmidt, Development of reaction models for complex gas phase reactions, paper presented in Chemical Reaction Engineering, Houston, ACS Symposium Series, No. 65, 1978.

23 G.F. Froment, Thermal cracking for olefins production. Fundamentals and their application to industrial problems, Chem. Eng. Sci., 36 (1981) 1271-1282.

24 K.M. Sundaram and G.F. Froment, Modeling of thermal cracking kinetics. 3. Radical mechanism for the pyrolysis of simple paraffins, olefins, and their mixtures, Ind. Eng. Chem., Fundam., 17 (1978) 174. 